\title{
Urine-derived Renal Epithelial Cells (URECs) as a source of biomaterial from ciliopathy patients for functional studies and diagnostics
}

\author{
H Ajzeberg ${ }^{1}$, G Slaats ${ }^{1}$, M Stokman², I Logister ${ }^{1}$, N Knoers ${ }^{2}$, R Giles ${ }^{1 *}$ \\ From Cilia 2014 - Second International Conference \\ Paris, France. 18-21 November 2014
}

\section{Objective}

Many ciliopathies are diagnosed in infants and children. Obtaining blood and/or skin biopsies for diagnostic and research purposes requires a visit to the clinic and a specialized sample collection skill. We sought alternative non-invasive sources of biomaterial from patients.

\section{Methods}

We have generated an approved Standard Operating Procedure to isolate and culture primary renal collecting duct cells from urine (URECs).

\section{Results}

We show that URECs are approximately $30 \%$ proximal tubule cells (megalin positive) and $70 \%$ collecting duct cells (AQP2 positive) from the patient. The cells grow on coverslips for immunocytochemistry, can be frozen and grow for 15-20 passages without immortalization. We demonstrate that whereas URECs from healthy individuals ciliate well, URECs from ciliopathy patients with nephronophthisis do not. URECs can form 3D spheroids to study patient-specific tubulogenesis defects. siRNA and overexpression "rescue" experiments in URECs make these cells amenable to functional studies complementing diagnostics. As a proof of principle we show how URECs can be used to test the relevance of genetic variants of "uncertain significance" obtained from whole-exome sequencing. Lastly, we have used patient URECs to explore pharmacological intervention on a patient-specific basis.

'Dept. Nephrology and Hypertension, University Medical Center Utrecht, Utrecht, The Netherlands

Full list of author information is available at the end of the article

\section{Conclusions}

This protocol expands the toolkit available to clinical geneticists and researchers alike in a child-friendly manner. Urine culture offers a non-invasive option for genetic and functional testing and does not require the family to go to the clinic for sample donation. We contend that UREC culture will facilitate personalized medicine for the ciliopathy community and beyond.

\section{Authors' details}

'Dept. Nephrology and Hypertension, University Medical Center Utrecht, Utrecht, The Netherlands. ${ }^{2}$ Dept. Medical Genetics, University Medical Center Utrecht, Utrecht, The Netherlands.

Published: 13 July 2015

doi:10.1186/2046-2530-4-S1-P51

Cite this article as: Ajzeberg et al:: Urine-derived Renal Epithelial Cells (URECs) as a source of biomaterial from ciliopathy patients for functional studies and diagnostics. Cilia 2015 4(Suppl 1):P51.

Submit your next manuscript to BioMed Central and take full advantage of:

- Convenient online submission

- Thorough peer review

- No space constraints or color figure charges

- Immediate publication on acceptance

- Inclusion in PubMed, CAS, Scopus and Google Scholar

- Research which is freely available for redistribution 